ISSN (Print): 2709-9636 | ISSN (Online): 2709-9644

Volume 2, 2021(Issue III, July to September)
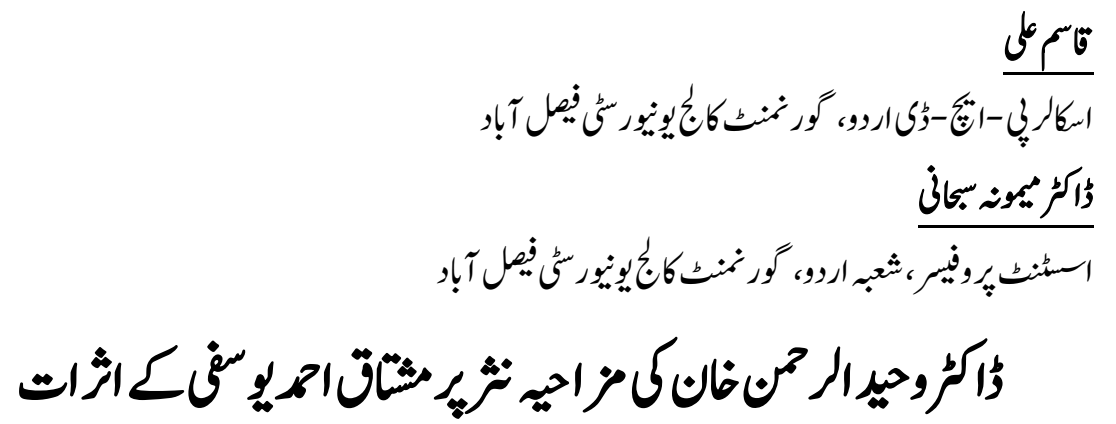

Qasim Ali

Scholar Ph.D Urdu, Government College University Faisalabad.

Dr. Mamuna Subhani

Assistant Professor, Department of Urdu, Government College University Faisalabad.

\title{
Influence of Mushtaq Ahmed Yousufi on Dr. Waheed- ur-Rehman Khan's Humorous Prose
}

In Urdu literature, satire and humor are found both in poetic and prosaic structures. It comes into existence as a result of social discrimination and ludicrous reaction. When the horse of power is out of control and no one dares to face it, it becomes necessary to take support from satire and humor. That is to say, satire and humor is a world sunk into the ocean of tears, society gripped in reconciliations, day-to-day new assaults of social values, bitter realities of life; it is an art to accept cruel truths and painful calamities and interestingly present them. As compared to other genres of literature, satire and humor are somewhat distinctive which gives it a different identity. Satire and humor is an art based on two basic and different elements; it springs by molding realities into joys and by committing to memory the common joys of life. Satire and humor in connection with Urdu literature just like the other genres of literature have their origin from the Persian language. In Urdu literature, there have been much unparalleled humorists who are themselves the identity of humor rather than the humor itself like Mirza Assadullah Khan Ghalib, Pitrus Bukhari, Rasheed Ahmed Siddiqui, Kanayah Laal Kapoor, Ibrahim Jalees, Shafiq-ur Rehman, Shaukat Thanvi, Ibn-e Insha, Mohammad Khalid Akhtar, Colonel Muhammad Khan, and 
ISSN (Print): 2709-9636 | ISSN (Online): 2709-9644

Volume 2, 2021(Issue III, July to September)

Mushtaq Ahmed Yousafi, etc. Mushtaq Ahmad Yousafi, the greatest humorist of the recent time has synchronized the tradition of satire and humor of Urdu literature in such a skilled and introspective way that it strikes the perception of everyone. He has expanded the treasure of Urdu humor in such a manner that levels it with international literature; he has gives the standard to satire and humor, not to speak of exceeding that standard even Yousafi could not exceed it; its evidence lies in his collections "AAbe Gum" "Shaame Shere Yaaraan." He has created such humorous literature that the tradition of Urdu humor will continually be indebted to him. The creations of Yousafi have not only given a new style and color to Urdu literature but also affected the humorists of the present era as well. This think-piece delves deep into these contemplative and skillful effects of the humor of Mushtaq Ahmad Yousafi and how he affected his contemporary humorist Dr. Waheed Ul Rehman and put effects on his literary creations.

Keywords: Literature, Humor, Mushtaq Ahmad Yousfi, Waheed-ulRehman, Authority, Treasure, Satire.

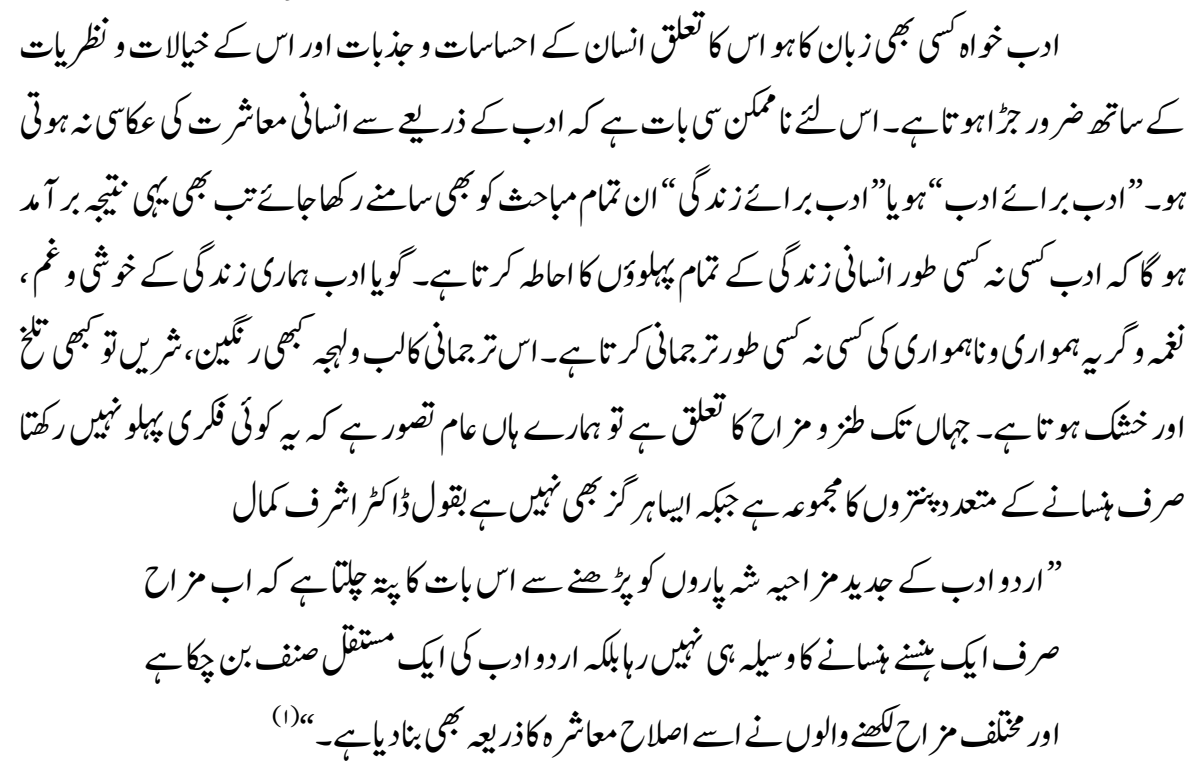




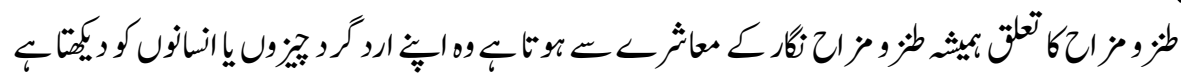

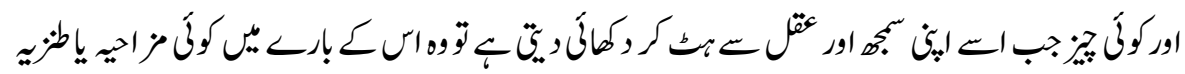

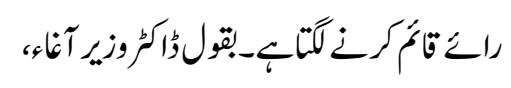

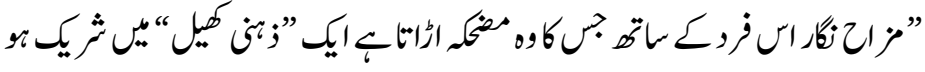

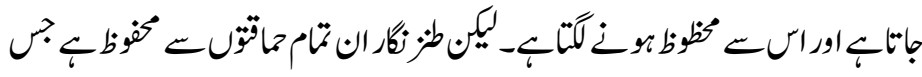

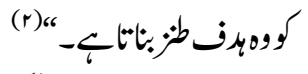

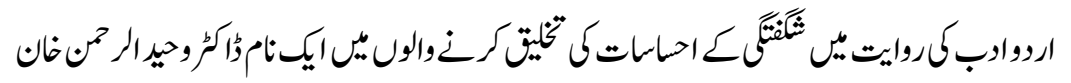

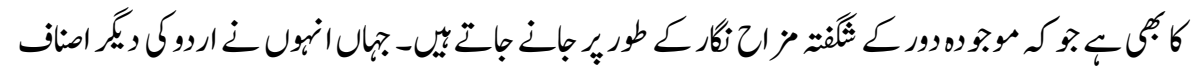

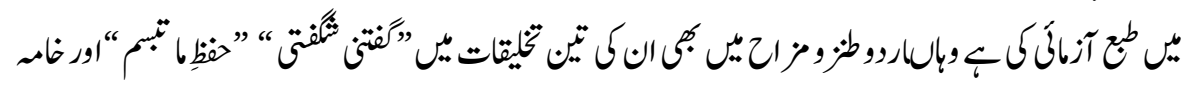

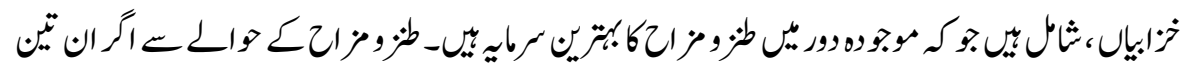

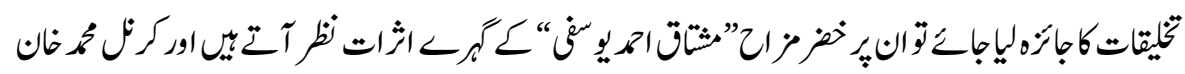

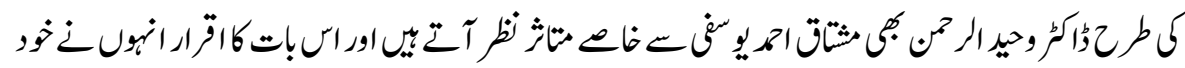

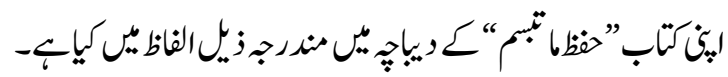

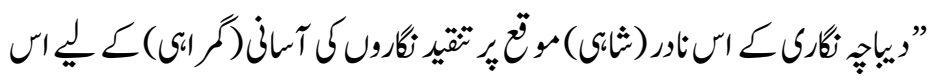

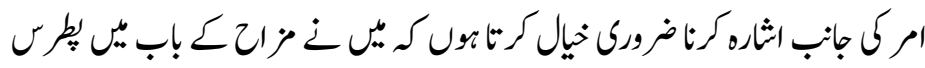

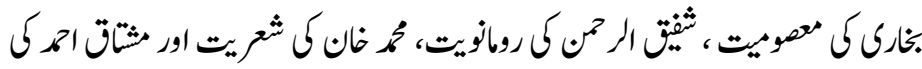

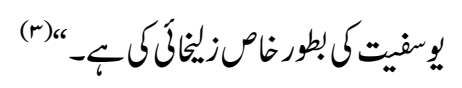

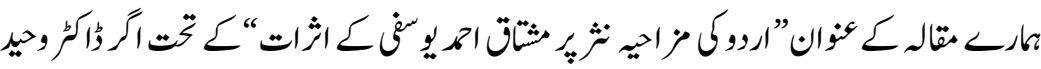

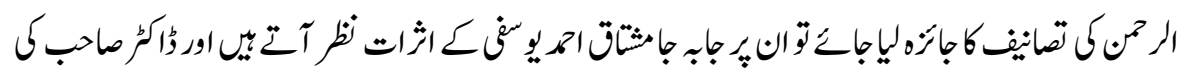

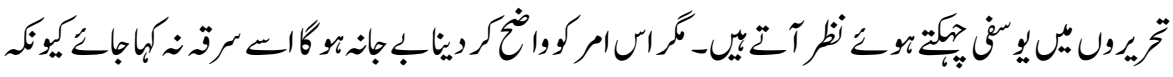

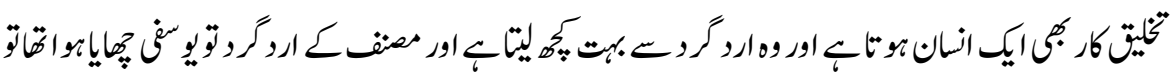

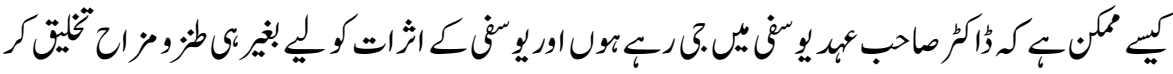

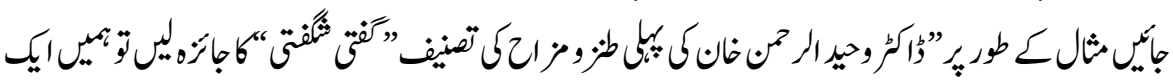


ISSN (Print): 2709-9636 | ISSN (Online): 2709-9644

Volume 2, 2021(Issue III, July to September)

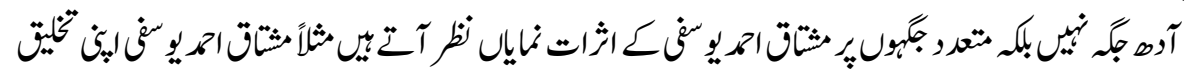

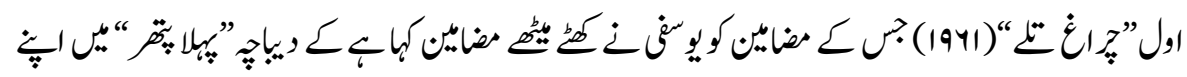

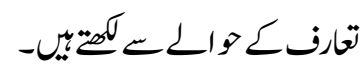

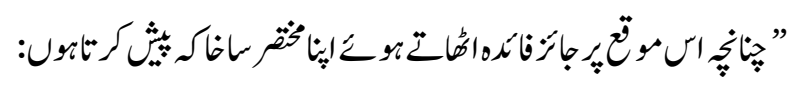

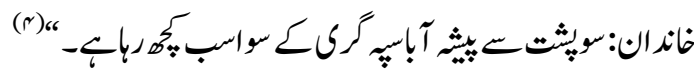

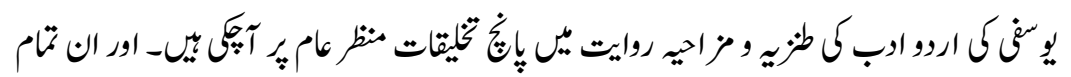

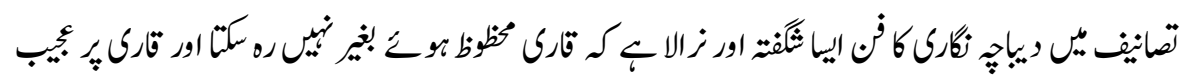

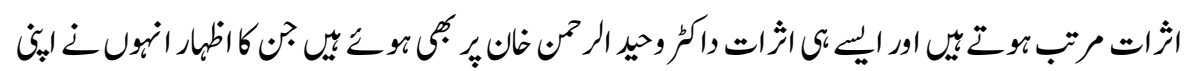

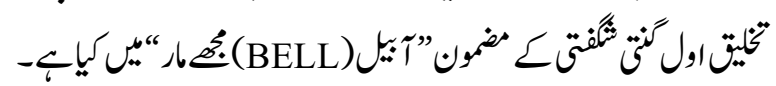

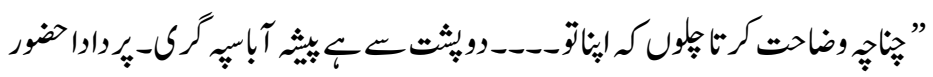

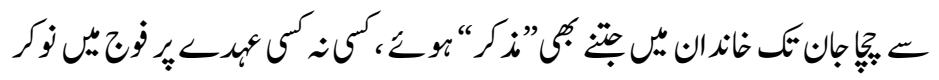

(a) “

"

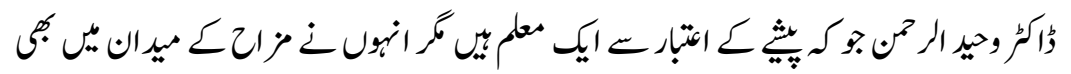

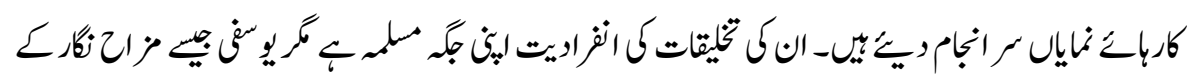

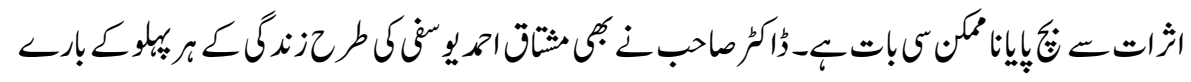

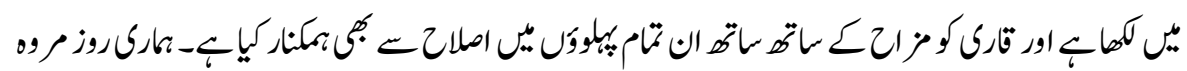

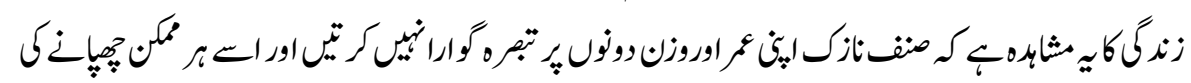

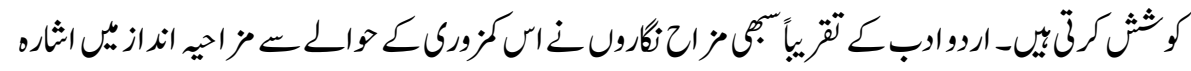

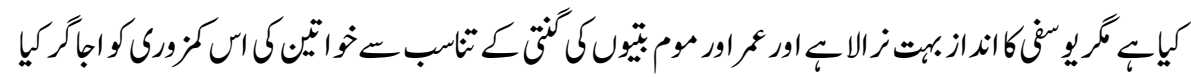

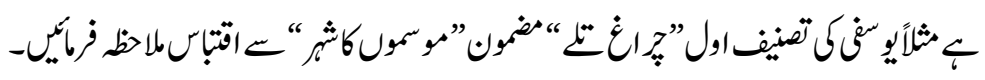

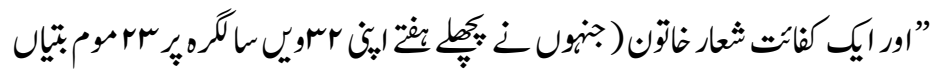

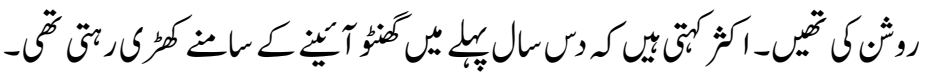


ISSN (Print): 2709-9636 | ISSN (Online): 2709-9644

Volume 2, 2021(Issue III, July to September)

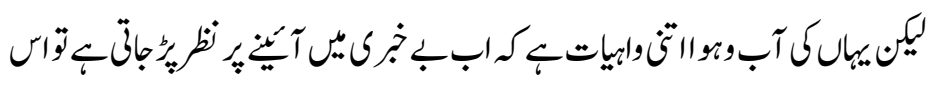

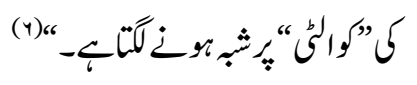

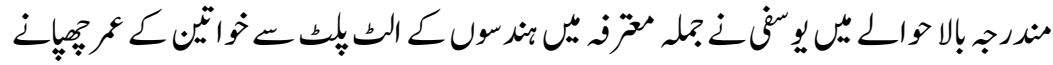

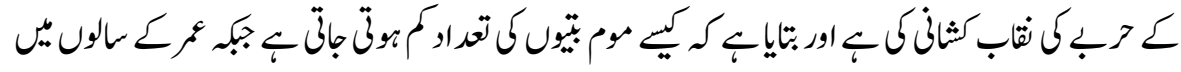

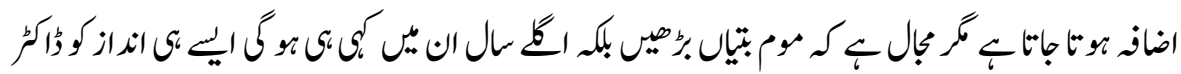

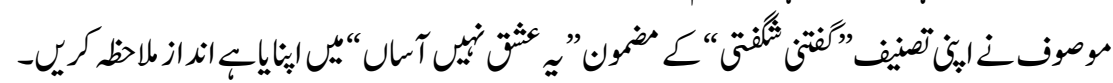

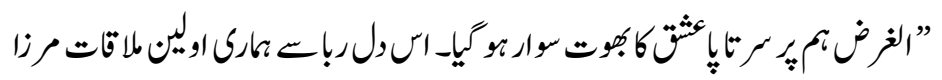

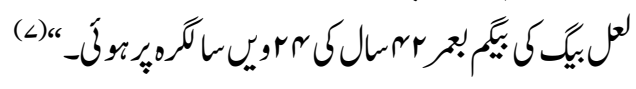

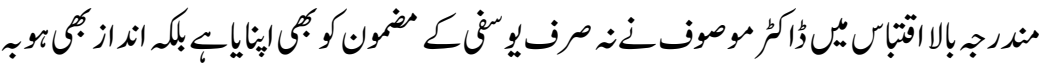

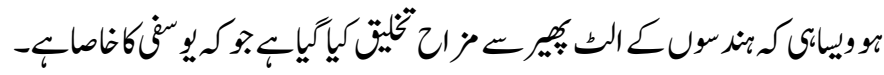

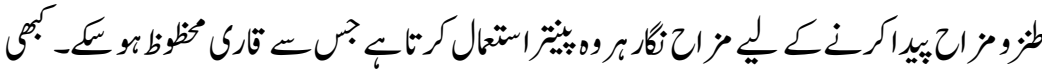

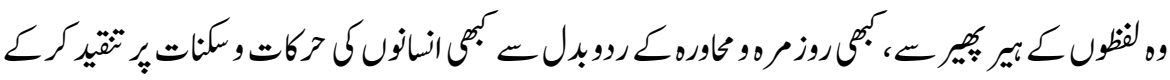

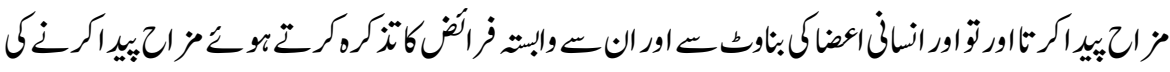

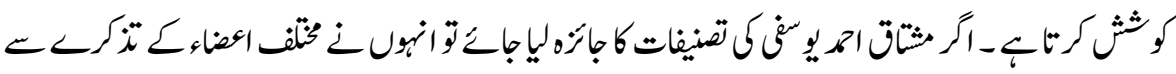

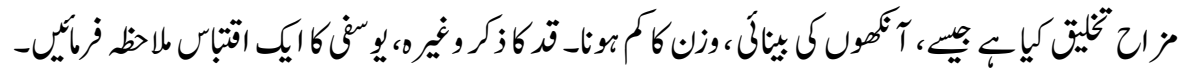

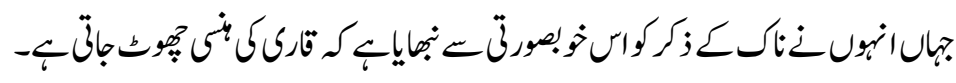

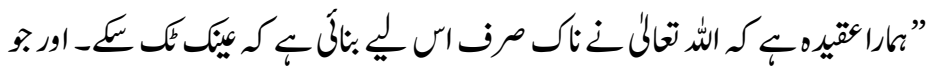

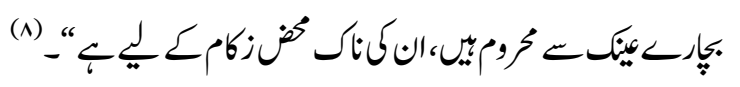

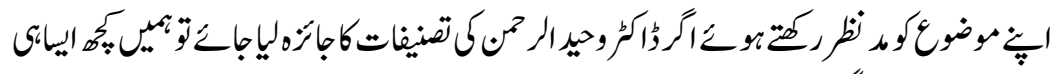

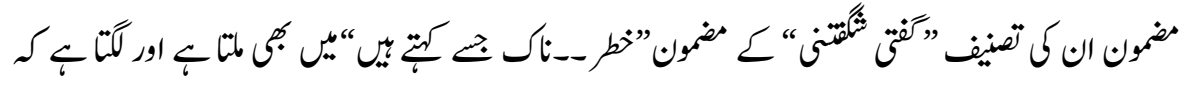

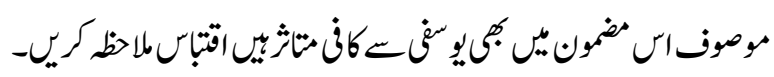

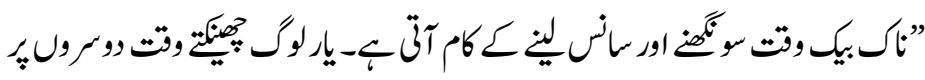

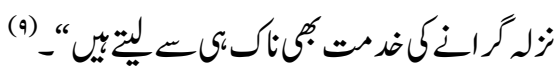




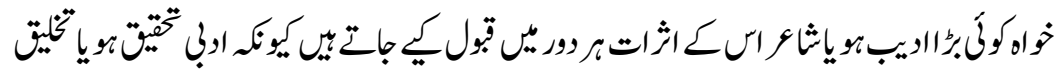

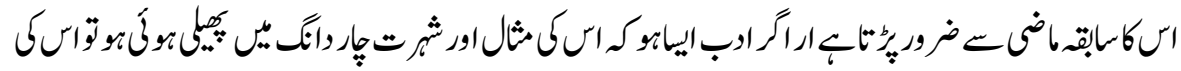

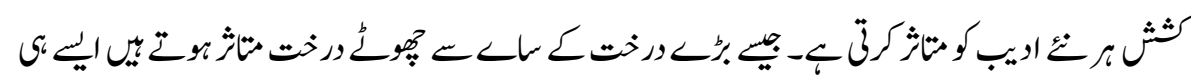

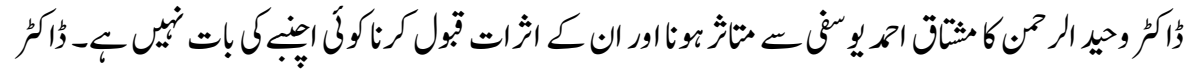

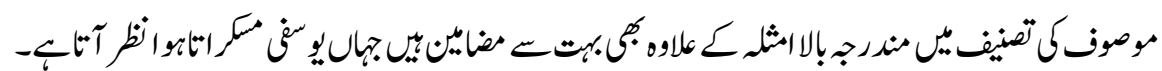

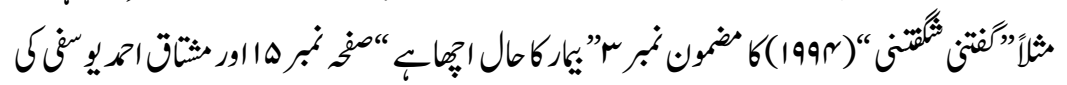

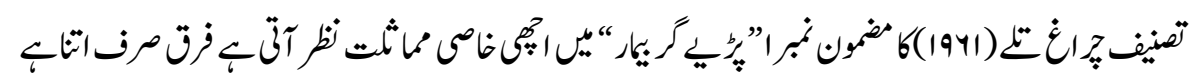

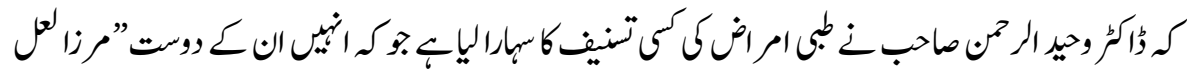

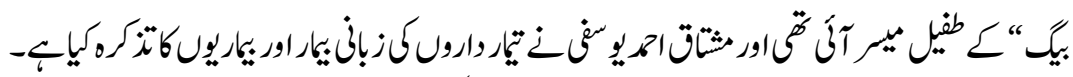

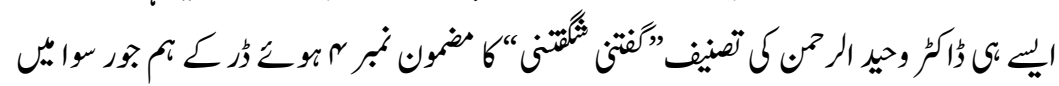

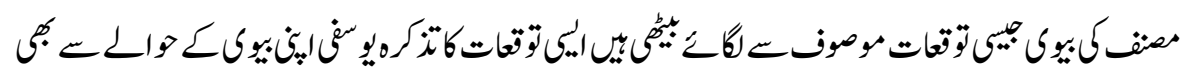
بتاعتيل-

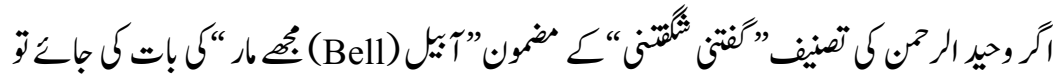

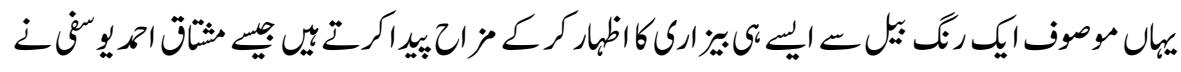

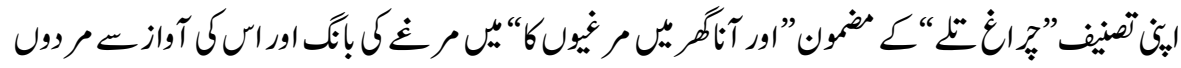

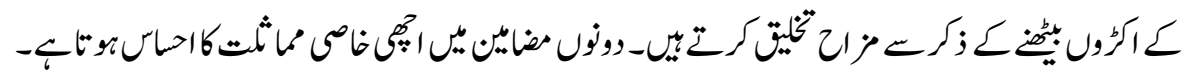

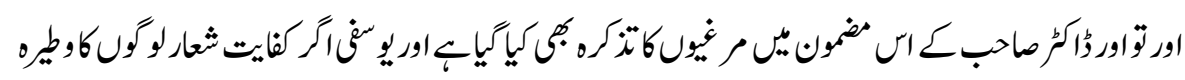

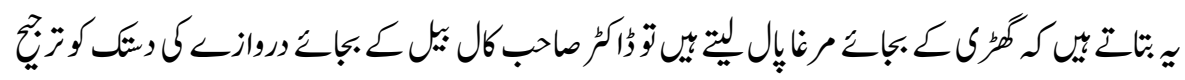
,

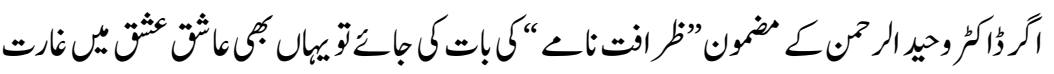

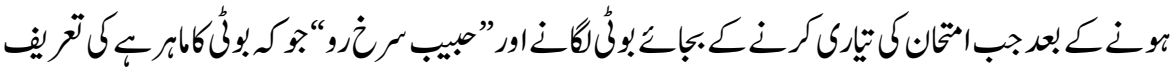

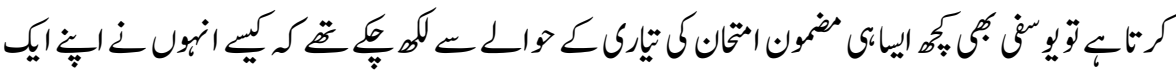

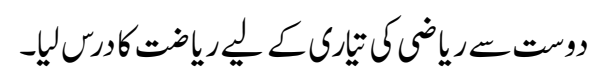




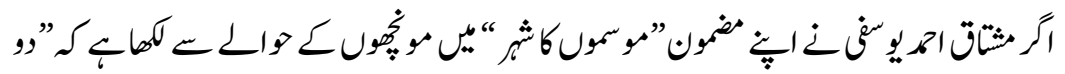

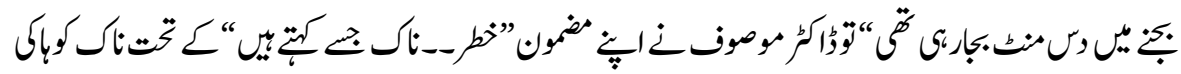

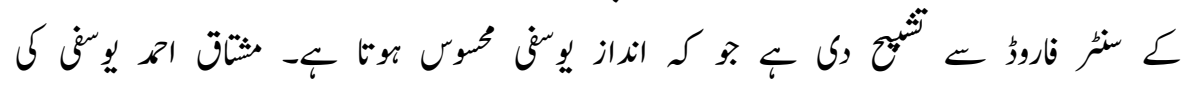

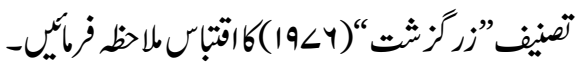

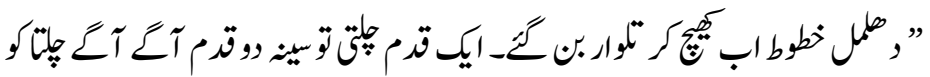

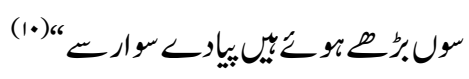

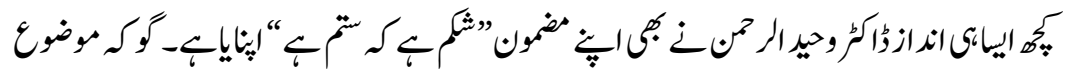

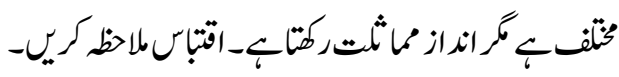

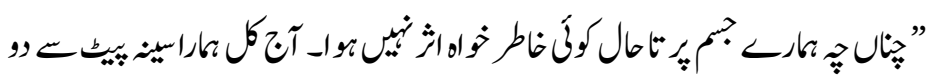

$$
\text { (11)، ق }
$$

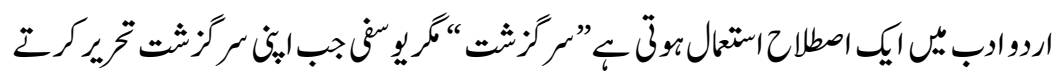

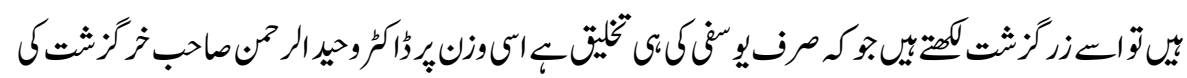

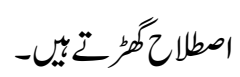

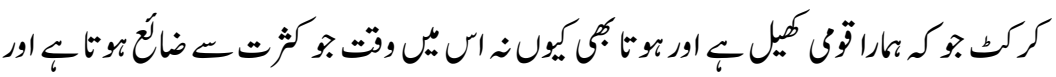

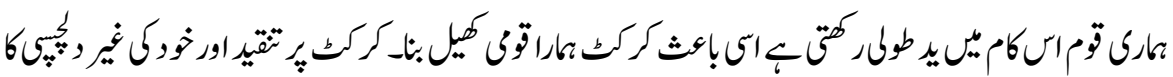

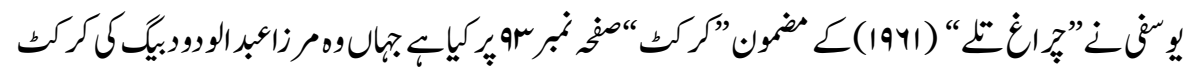

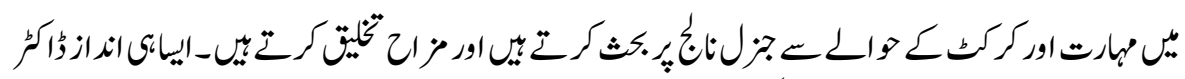

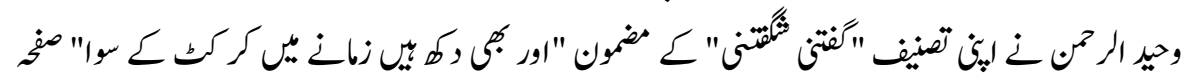

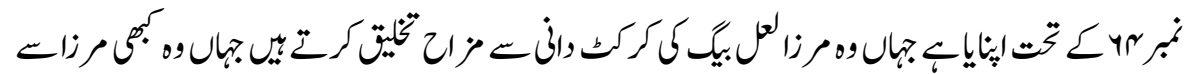

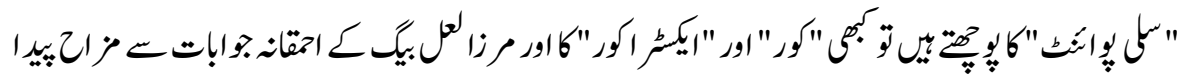

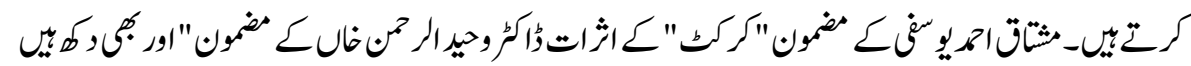

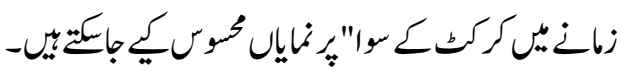




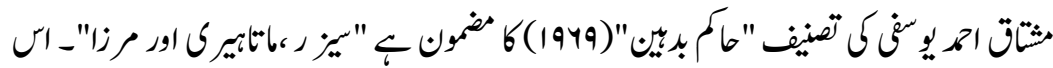

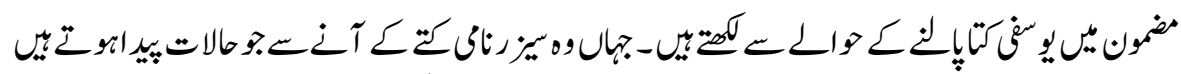

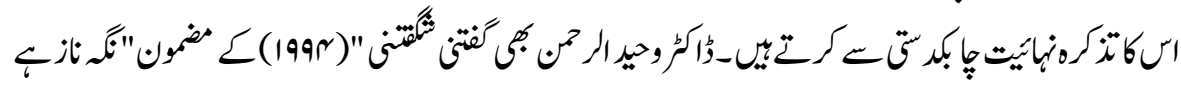

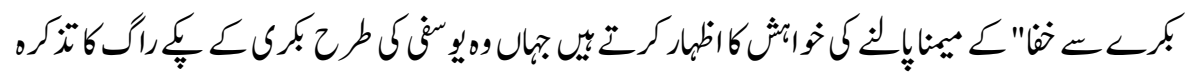

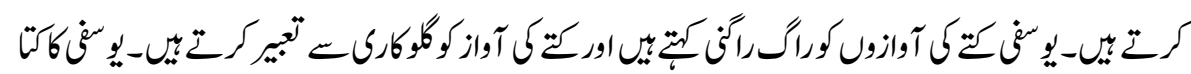

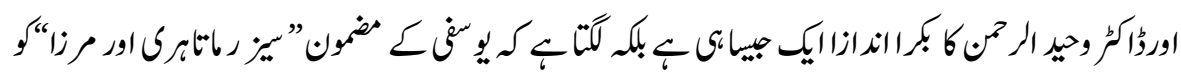

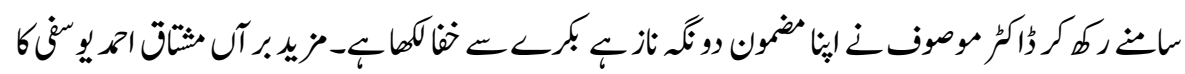

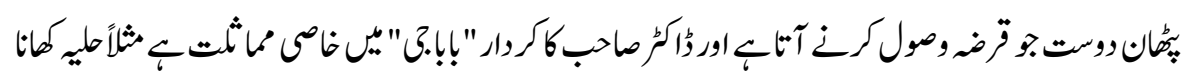
بيناونير

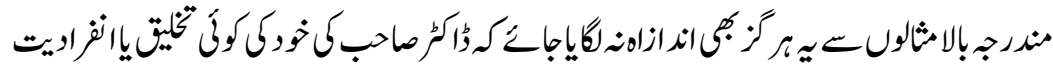

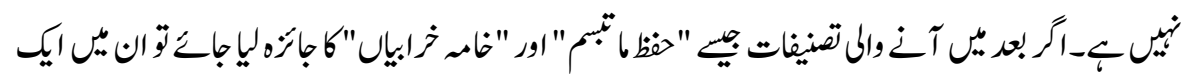

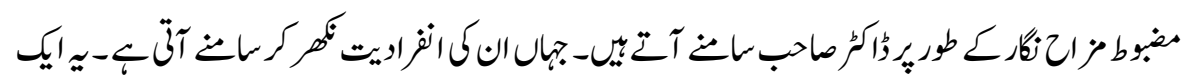

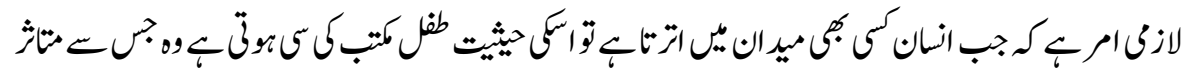

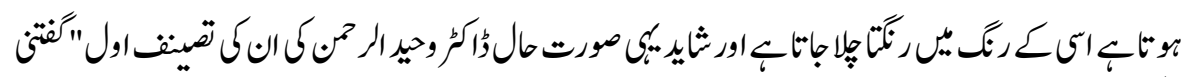

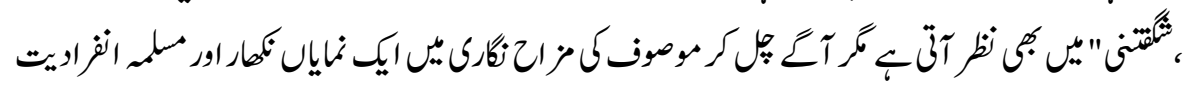

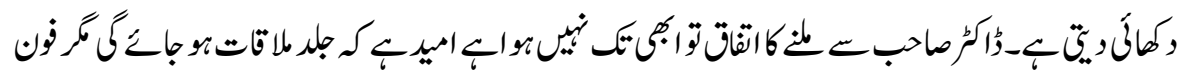

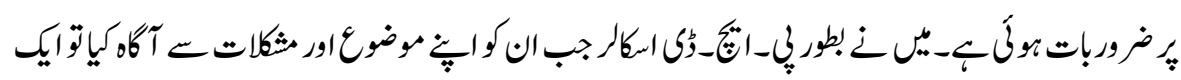

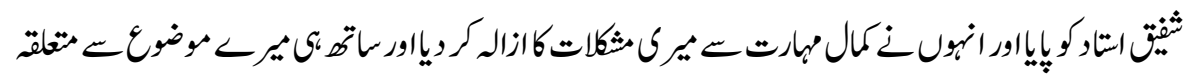

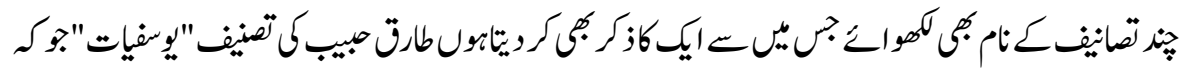

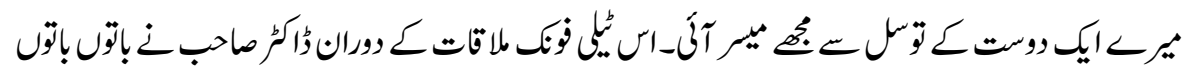

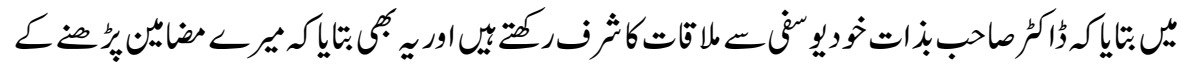

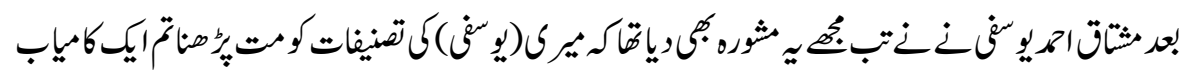

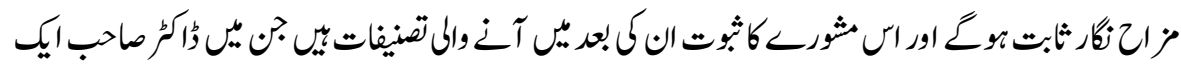




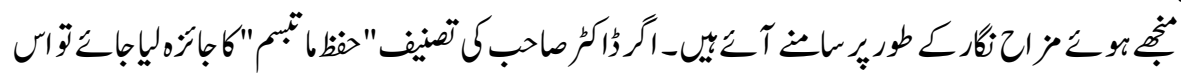

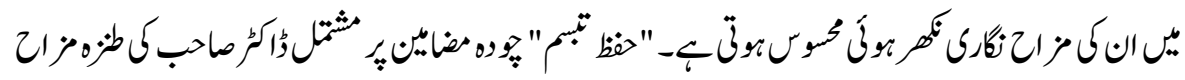

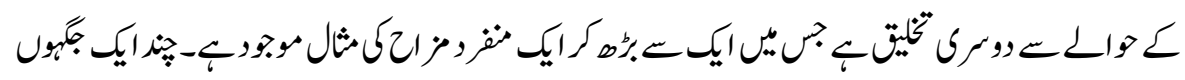

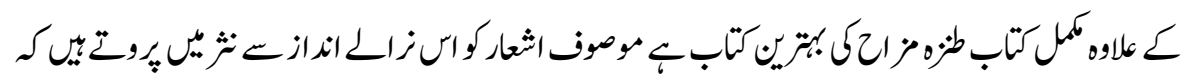

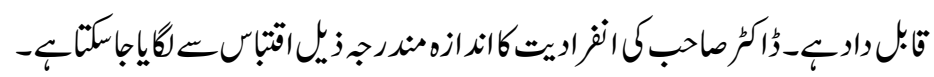

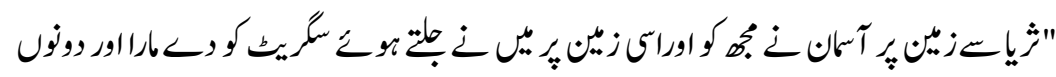

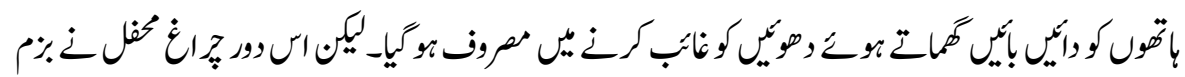

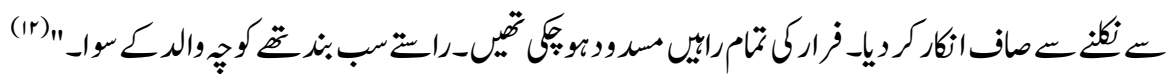

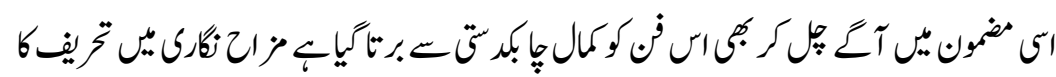

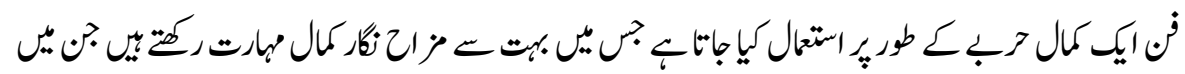

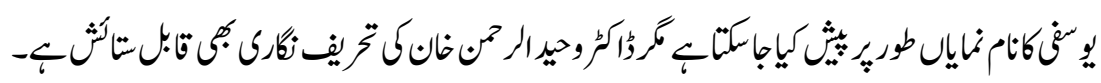

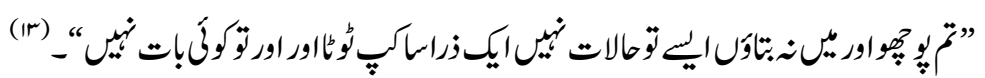

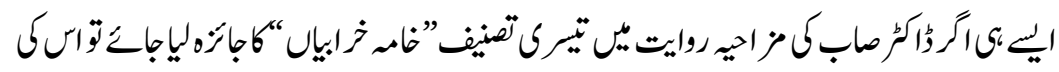

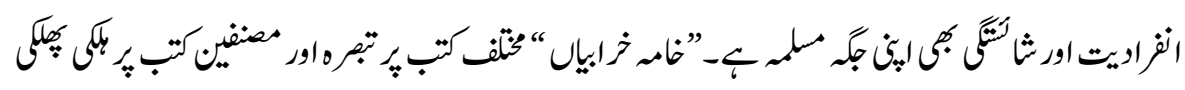

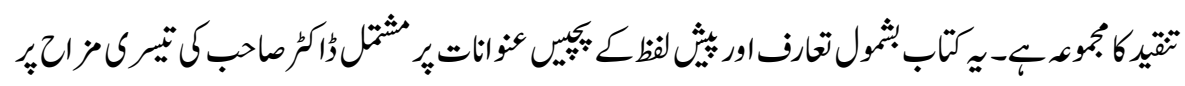

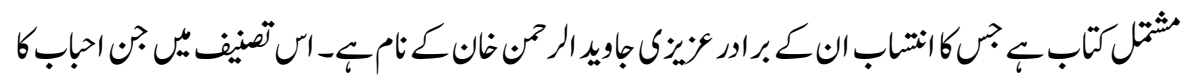

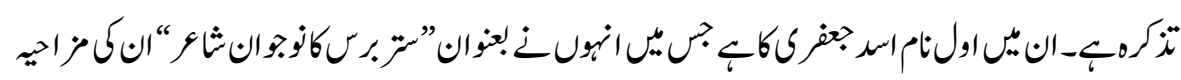

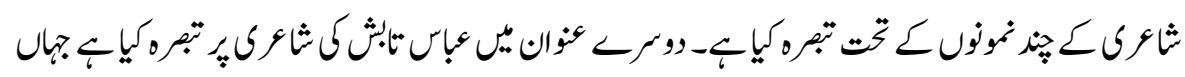

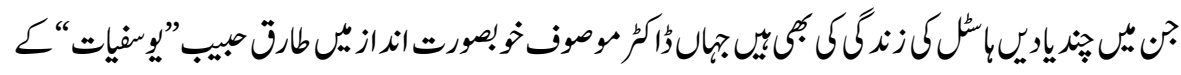

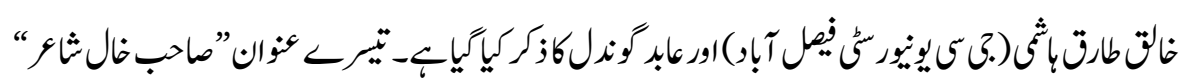

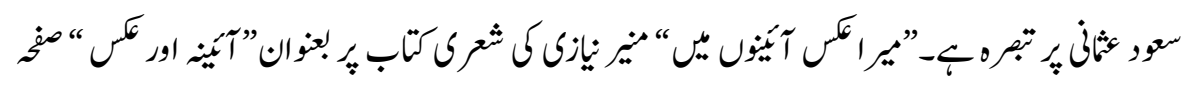

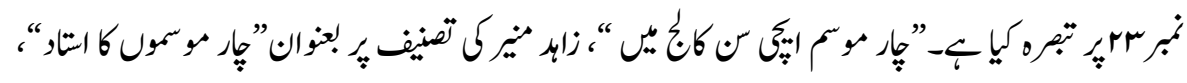

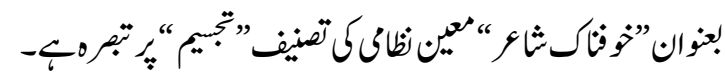


ISSN (Print): 2709-9636 | ISSN (Online): 2709-9644

إن

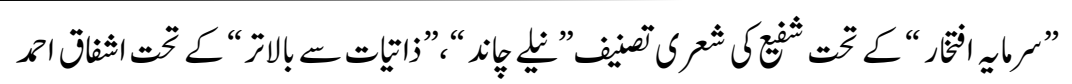

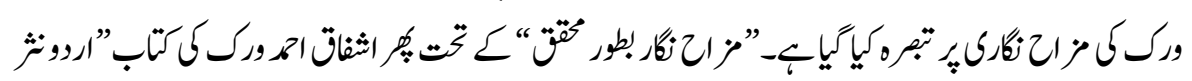

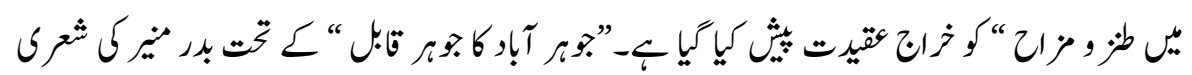

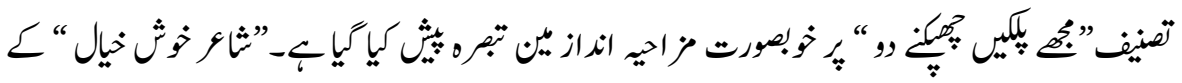

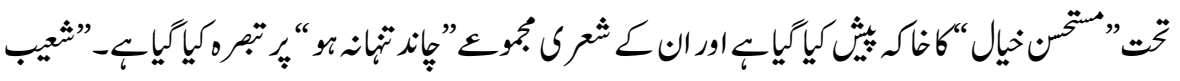

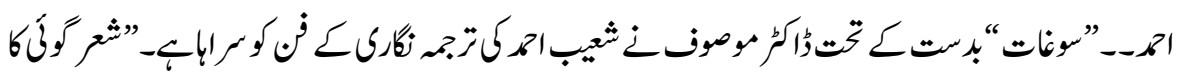

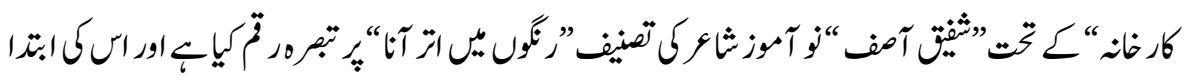

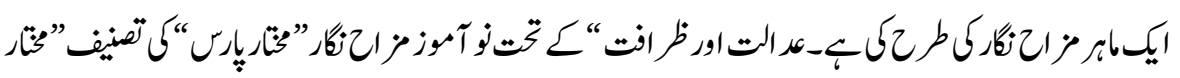

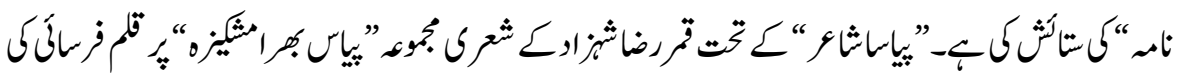

كئك

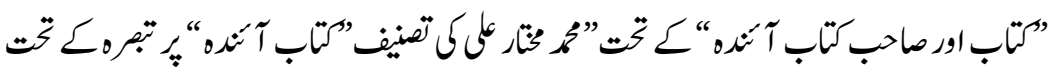

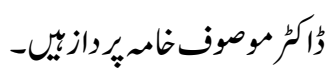

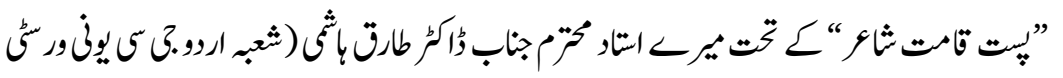

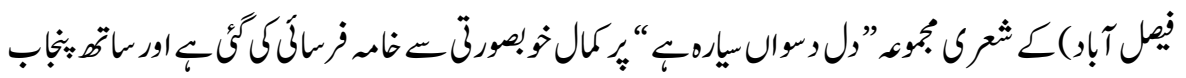

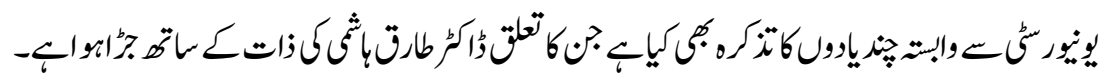

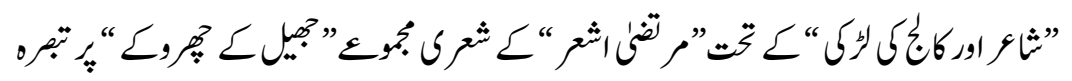

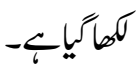

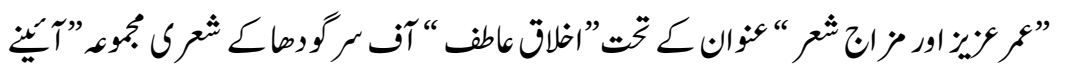

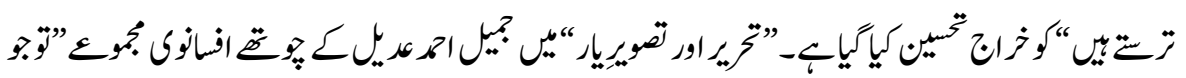

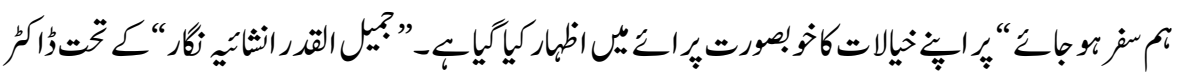

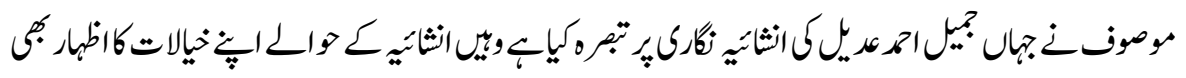

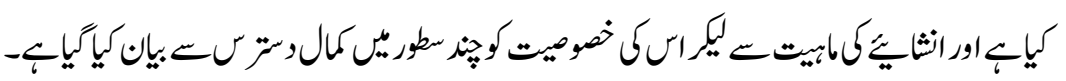

104 


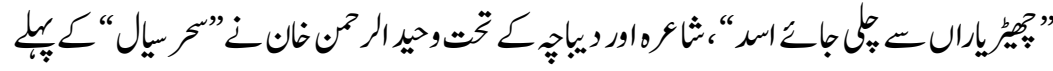

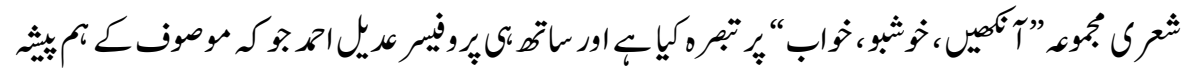

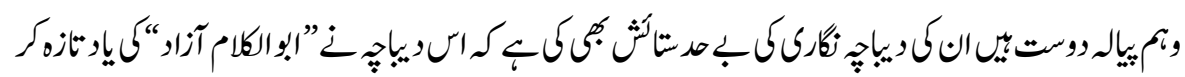

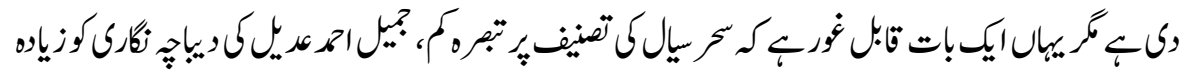

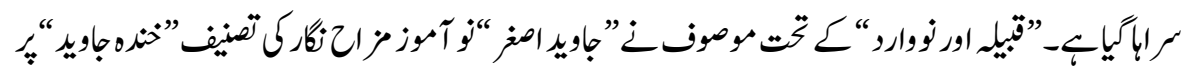

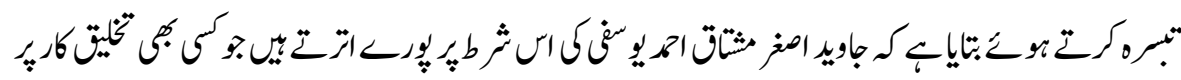

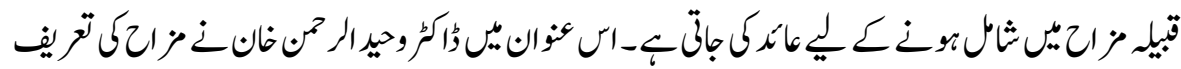

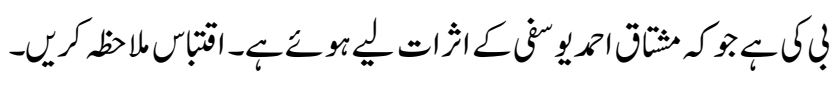

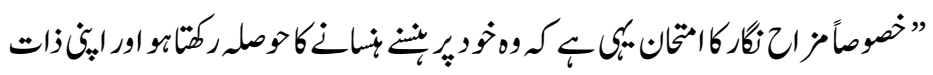

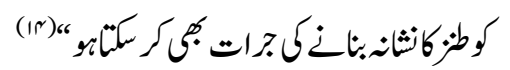

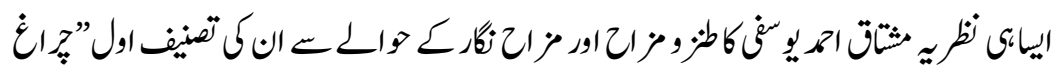

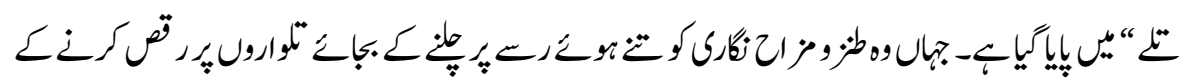

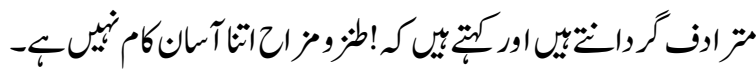

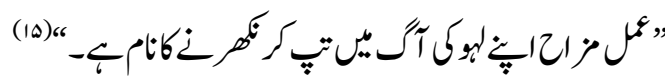

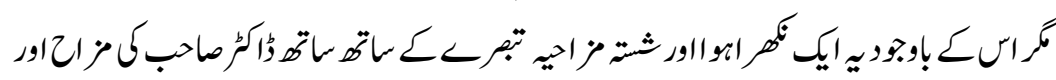

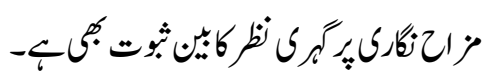

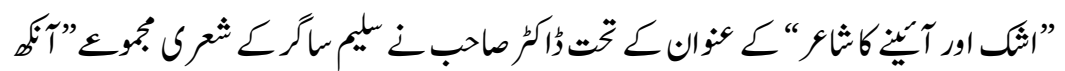

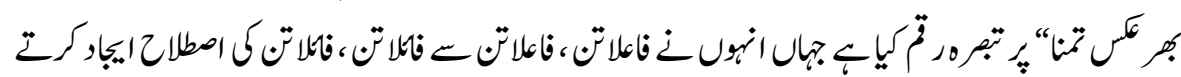

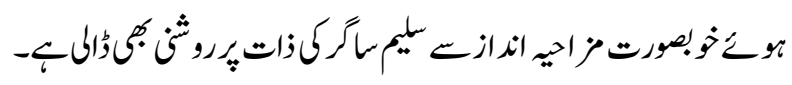

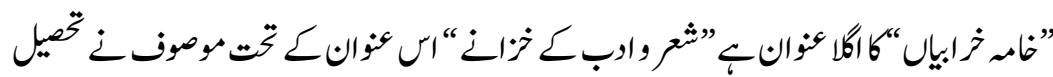

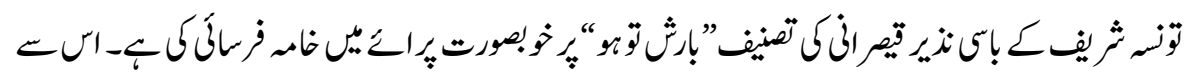

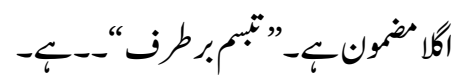




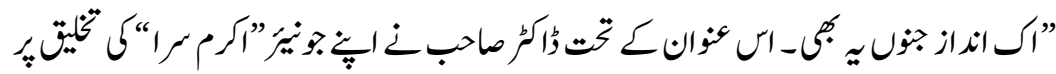

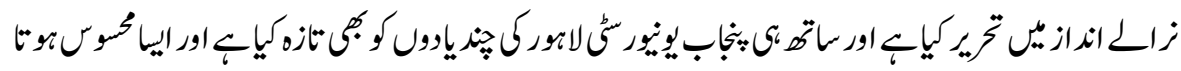

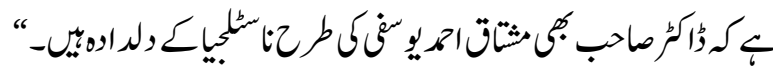

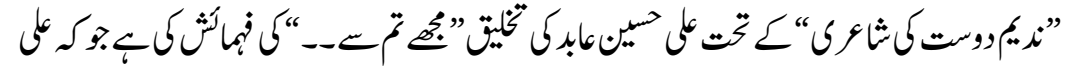

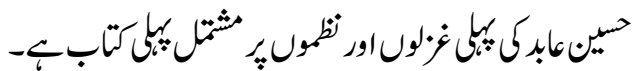

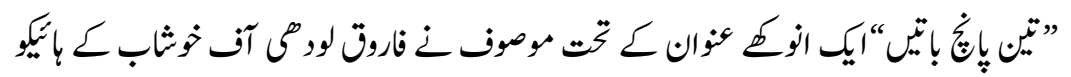

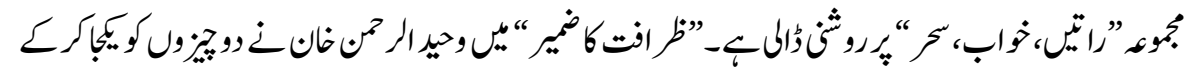

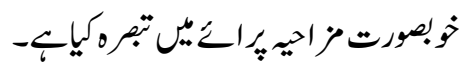

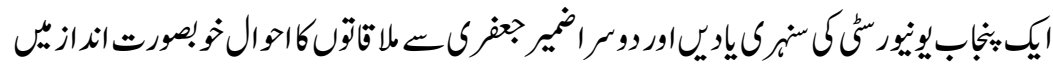

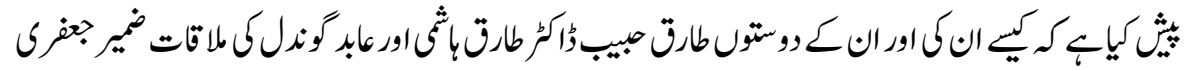

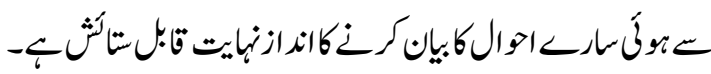

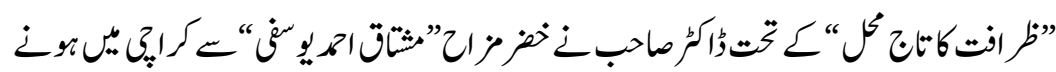

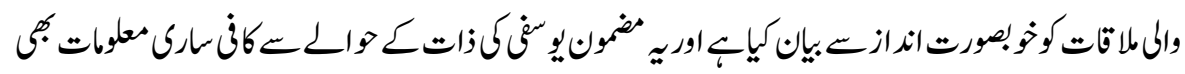

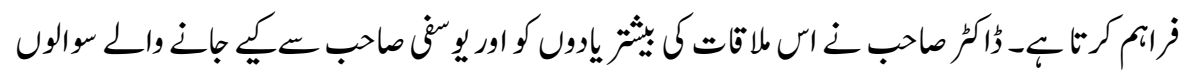

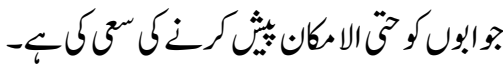

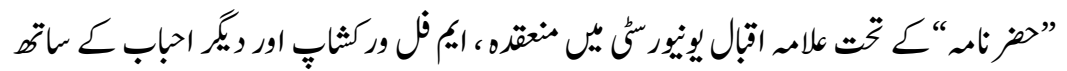

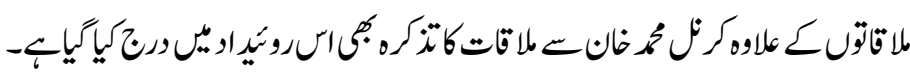

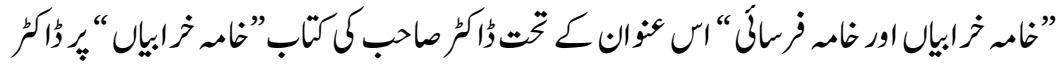

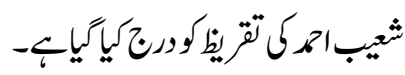

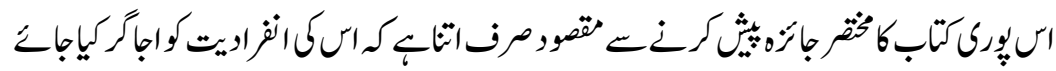

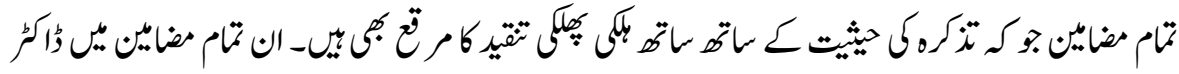

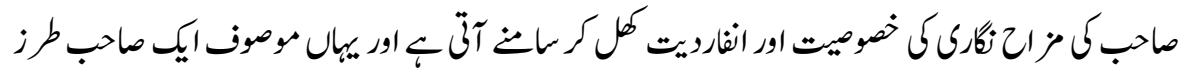

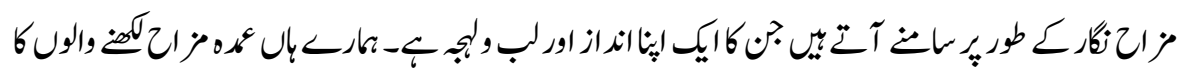


ISSN (Print): 2709-9636 | ISSN (Online): 2709-9644

Volume 2, 2021(Issue III, July to September)

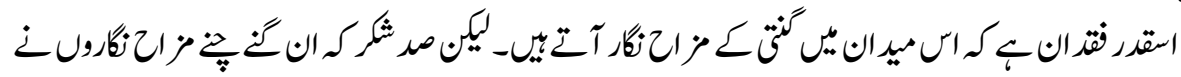

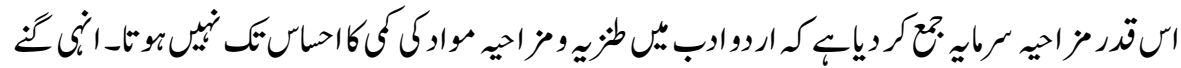

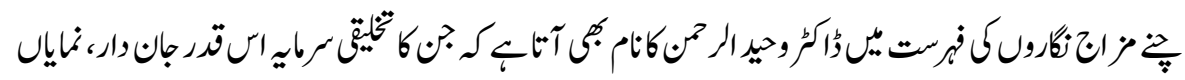

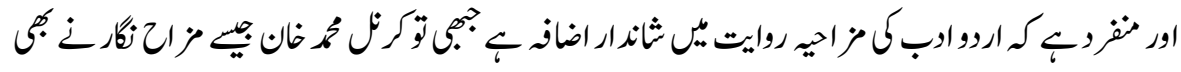

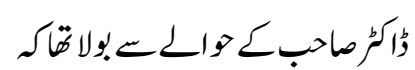

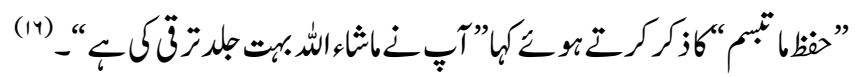

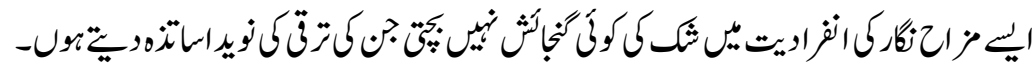

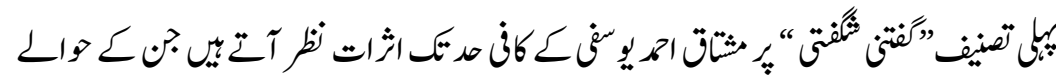

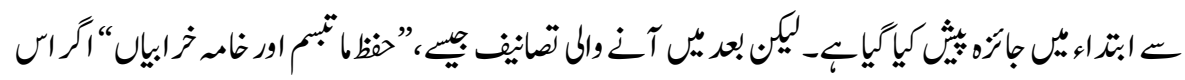

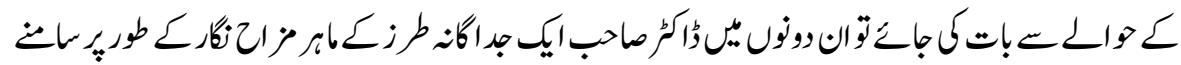

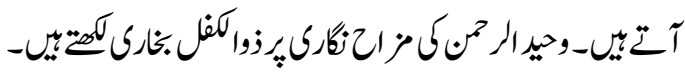

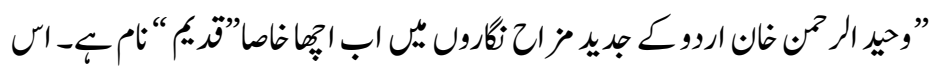

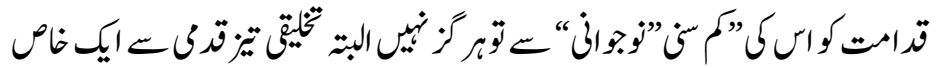
(1 1 )،

$$
\text { نبتتب }
$$

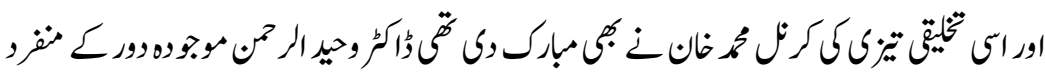

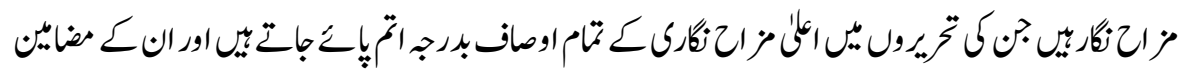

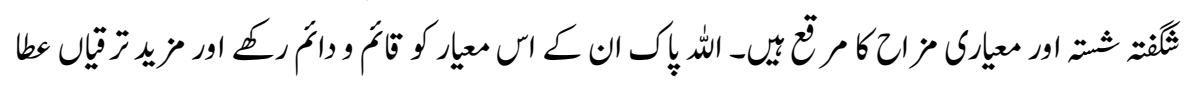
ز

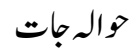

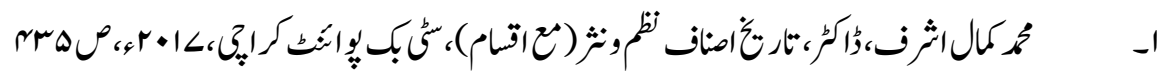

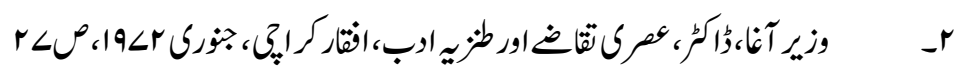

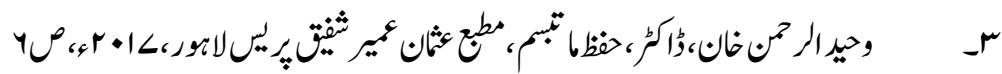

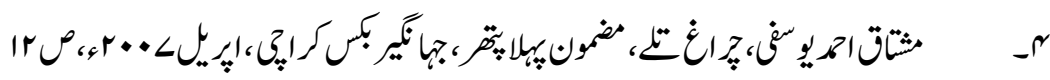


ISSN (Print): 2709-9636 | ISSN (Online): 2709-9644

Volume 2, 2021(Issue III, July to September)

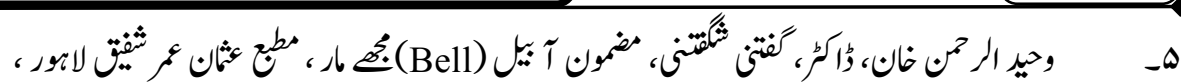

$$
r \Lambda-r \angle \rho^{2} r+1 \angle
$$

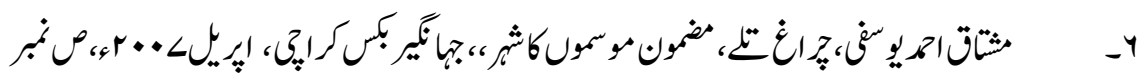

$\operatorname{lir}$

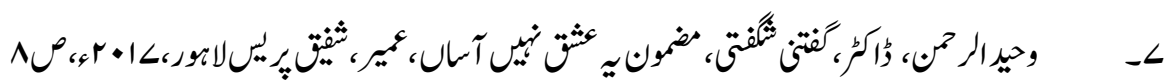

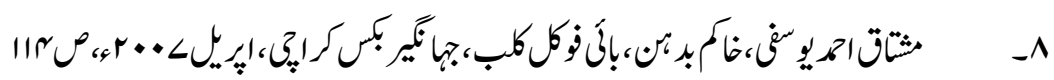

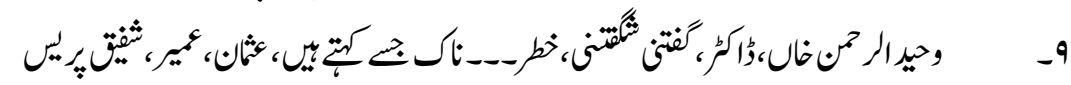

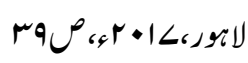

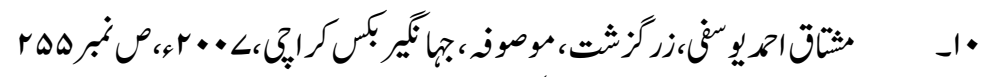

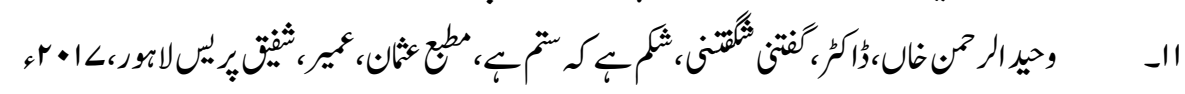

$$
\text { ص }
$$

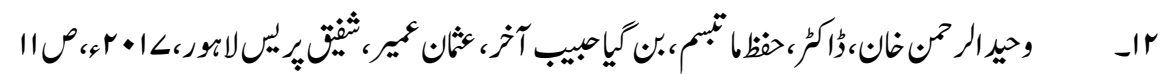

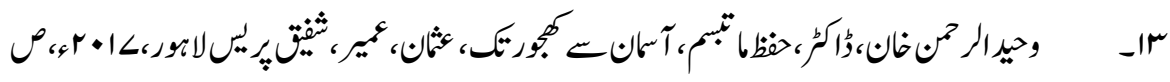

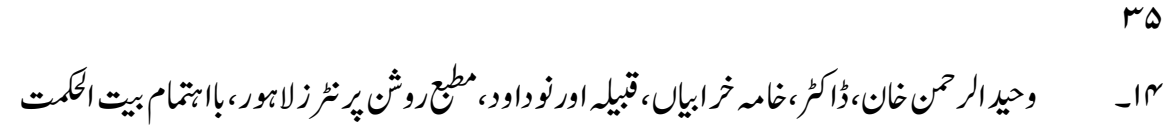

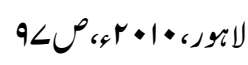

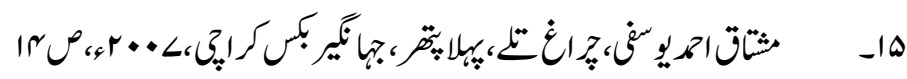

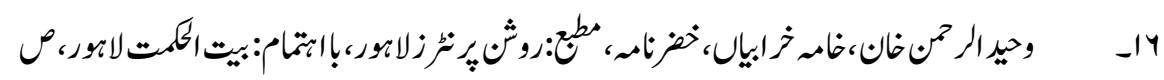

|rime

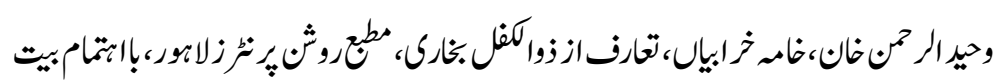
$-1<$

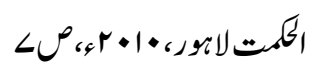

